\title{
An Assessment of Antioxidant and Antiproliferative Activities of Super Grain Quinoa
}

Sikha Bhaduri*

CUNY School of Public Health, NY 10035, USA

\begin{abstract}
Quinoa is known to be an excellent source of natural antioxidants and therefore the extract of quinoa seed was considered to have a significant anti-inflammatory activity. Two different varieties of quinoa seeds and six different solvents hexane, acetone, methanol, ethanol, ethyl acetate and water were used as solvent for extraction in the present study. Extracts from water, methanol and ethanol showed significant antioxidant and phytochemical activities. Water extract showed highest Phenol content (89.73 \pm $1.74)$, antioxidant activity $(1586 \pm 41.42)$ and DPPH scavenging capacities $(82.71 \pm 0.03)$ compared to other solvents used for extraction. IC50 value for percentage DPPH scavenging capacities by water extract was $14.71 \pm 0.02$, compared to ascorbic acid $(7.15 \pm 0.13)$, which is a control. All extracts exhibit significantly high levels of flavonoid content. Ethyl acetate extract represented highest $(88.41 \pm 0.37) \mathrm{NO}$ scavenging capacity. Lowest IC50 value $(52.58 \pm 0.14)$ for NO scavenging capacity was identified for ethanol extract compared to control (24.19 \pm 3.53$)$. Ascorbic acid used as control in both DPPH and Nitric oxide scavenging capacities measurement. Quinoa seed extracts from all six solvents found to have antimicrobial activities towards gram positive bacteria but not towards all gram negative bacteria. All extracts showed significant anti proliferative activities towards $P 116$ cells.
\end{abstract}

Keywords: Quinoa seed; Extract; Antioxidant activity; Extraction; Scavenging; $\mathrm{IC}_{50}$ value

\section{Introduction}

Normally, there is a balance between the quantities of free radicals generated in the body and the antioxidant mechanisms scavenge/ quench these free radicals preventing them from causing deleterious effects in the body. But, many detrimental diseases such as periodontal disease, metabolic bone diseases, diabetes mellitus, atherosclerosis, neurodegenerative diseases are characterized by an enhanced state of oxidative stress and are associated with the overproduction of reactive oxygen species (ROS) and/or a decrease in antioxidant defenses, leading to impose oxidative stress in the body [1]. Oxidative stress can be defined as an excessive amount of Reactive species (RS), which is the net result of an imbalance between production and destruction of RS, and which is regulated by antioxidant defenses. RS is a collective term that includes both oxygen radicals and other reactive oxygen and nitrogen species (ROS/RNS). Reactive oxygen (ROS) and nitrogen (RNS) species are products of normal cellular metabolism, which, at high concentrations, thought to be important mediators of damage to cellular structures, such as nucleic acids, lipids and proteins. Oxidation in the living system is essential for generation of energy due to catabolism but prolonged oxidative stress result in the continuous production of free radicals and reactive oxygen species (ROS), which can lead to permanent damage of the body organs leading to chronic disorders such as heart diseases, diabetes, cirrhosis, malaria, neurodegenerative diseases, AIDS, cancer, and premature aging $[2,3]$. ROS includes free radicals such as superoxide anion radicals $\left(\mathrm{O}^{2-}\right)$, hydroxyl radicals $(\mathrm{OH})$ and non-freeradical species such as $\mathrm{H}_{2} \mathrm{O}_{2}$ and singled oxygen are various forms of activated oxygen. Oxidative damage to biomolecules such as proteins, lipids, and DNA is also thought to accumulate with ageing, leading to the pathogenesis of many age-related diseases [4]. Oxidative damage to DNA is considered a critical step in cancer development [5].

It is well-known that diets rich in fruit and vegetables are protective against cardiovascular disease and certain forms of cancer and perhaps against other diseases also [6]. Celiac Disease (CD), an systematic autoimmune enteropathy, currently $\mathrm{CD}$ is thought to resemble multisystem immunological disorder rather than a disease restricted to the gastrointestinal tract $[7,8]$, characterized by chronic inflammation of the intestinal mucosa, atrophy of intestinal villi and a permanent intolerance to gluten protein [9]. Plants have been used as traditional medicine system throughout the world for many years since they are rich in a wide variety of phytochemical compounds, which are good sources of antioxidants [10]. Following antioxidant hypothesis coined by Gey [11], it was thought that an increased intake of antioxidants found in biological system via dietary supplements might lower the risk of diseases that involve oxidants. A growing number of observational studies has examined the association between the intake of foods rich in polyphenols (onions, apples, tea, cocoa, red wine) and chronic diseases as well as the relation between the intake of individual dietary flavonoids and chronic diseases [12]. The antioxidant defense mechanism has led to the concept that increased antioxidant defenses might lower the risk of diseases that involve oxidants and free radicals generated from endogenous metabolic systems, such as, inflammation, aerobic respiration, exercise etc. and from exogenous systems such as, tobacco smoking, air/other pollution, radiation and UV-light and thus protect DNA, proteins and lipids from oxidative damage [4]. High antioxidant capacity is provided mainly by their phenolic contents and the beneficial effects of the polyphenols are known. Due to their antioxidant activities polyphenols might also enhance the antioxidant defense of the body. These properties have been demonstrated in various in vitro and ex vivo models [4].

Quinoa (Chenopodium quinoa Willd) a pseudo cereal belonging to the Chenopodiaceae family, has been considered to be a functional

*Corresponding author: Sikha Bhaduri, CUNY School of Public Health, NY 10035, USA, Tel: +1 212396 7789; E-mail: sbhaduri@hunter.cuny.edu

Received December 02, 2015; Accepted December 29, 2015; Published January 08,2016

Citation: Bhaduri S (2016) An Assessment of Antioxidant and Antiproliferative Activities of Super Grain Quinoa. J Food Process Technol 7: 549. doi:10.4172/2157-7110.1000549

Copyright: $\odot 2016$ Bhaduri S. This is an open-access article distributed under the terms of the Creative Commons Attribution License, which permits unrestricted use, distribution, and reproduction in any medium, provided the original author and source are credited. 
food and it has gained increasing interest in recent years due to its high nutritional value. Quinoa also acts as a cell protector and presents an important source of antioxidants [13] due to its polyphenolic phytonutrient constituents, and therefore could be used for medicinal purposes in humans $[14,15]$. This gluten free pseudocereal recommended to be used as an ingredient in food such as bread, pasta or baby food and also in common diets [16], since; only effective treatment [17] for celiac disease (CD) is a life-long gluten-free diet. Despite its slightly bitter taste, quinoa flour produces acceptable gluten free baked products [18] that are high in fiber and rich in antioxidants. However, plants rich in phytonutrients may play an important role in inhibiting both free radicals and oxidative chain reactions within tissues and membranes [19].

Therefore due to its excellent nutritional, functional and technological properties, exceptional antioxidant activities and phytonutrient contents, Chenopodium quinoa might has a potential ability to be used as a naturally occurring food preservative also to inhibit microbial growth along with its anti-inflammatory activities, which probably needs a more in depth investigation. Development of cost effective isolation procedures that yield standardized extracts as well as safety and toxicology evaluation of quinoa requires a deeper investigation [20]. Due to the complex nature of phytochemicals, a single method cannot evaluate the antioxidant activities of the seed. Therefore several standard methods were used. Considering all these, the proposed study was aimed to evaluate the antioxidant and anti-inflammatory properties and activities of super grain quinoa phytochemicals.

\section{Materials and Methods}

\section{Preparation of extracts}

The quinoa seeds were powdered with a mechanical grinder to obtain a coarse powder, which were then subjected to extraction using a modified method [21] with hexane, acetone, methanol, ethanol, ethyl acetate and water. Briefly, $2 \mathrm{~g}$ of seed powder were extracted with $20 \mathrm{~mL}$ of solvent into a $50 \mathrm{~mL}$ polyethylene centrifuge tube. The mixture was kept on a rotary shaker at speed 5 for 24 hours at room temperature. After 24 hours, the filtrate was centrifuged at $5000 \mathrm{~g}$ for 10 minutes, the supernatant was collected. The extraction was done at least three times with the residues and supernatants collected each time. All the collected supernatants were pulled out together and were filtered through Whatman No. 1 paper filter and concentrated to a dry mass with the aid of a rotary evaporator. Two different varieties of quinoa seeds grain type I and grain type II from two different companies were selected to get extracts from hexane, acetone, methanol, ethanol, ethyl acetate and water as solvent. Therefore, two different sets of extracts from each of two different grains I and II were obtained. Each dried extracts were dissolved in $1 \mathrm{ml}$ dimethyl sulfoxide (DMSO).

\section{Determination of total phenolic content}

The amount of total soluble phenolic content in different seed extracts was determined according to Folin-Ciocalteu method [22] with slight modifications. Briefly, $10 \mu \mathrm{L}$ of the sample extract or a series of gallic acid standards $(0,20,40,60,80$, and $100 \mathrm{mg} / \mathrm{l})$ from the stock solution was mixed with $100 \mu \mathrm{L}$ of Folin-Ciocalteu reagent (Sigma Chemical Co., St. Louis, Mo., USA). After 10 min of incubation, 300 $\mu \mathrm{L}$ of $20 \% \mathrm{Na}_{2} \mathrm{CO}_{3}$ solution was added and the volume was adjusted to $1 \mathrm{~mL}$ using deionized water. The mixture was incubated in dark for 2 hours at room temperature and the absorbance was measured at 750 $\mathrm{nm}$ using a microplate spectrophotometer (Bio-Rad Laboratories, Inc., 2000 Alfred Nobel Drive, CA 94547, USA) against blank sample. The total phenolic content was measured as gallic acid equivalents per gram of dry mass (mg GAE/g dw) and the values were presented as means of triplicate analysis.

\section{Determination of total flavonoid content}

Total flavonoid content was estimated by a modified colorimetric method [23] by taking $20 \mu \mathrm{L}$ of each extract and mixed with $500 \mu \mathrm{lde}-$ ionized water and $30 \mu \mathrm{l}$ of $5 \%$ sodium nitrite $\left(\mathrm{NaNO}_{2}\right)$ solution. After $5 \mathrm{~min}$ of incubation at room temperature, $60 \mu \mathrm{l}$ of $10 \%$ Aluminium chloride $\left(\mathrm{AlCl}_{3}\right)$ solution was added. Subsequently, $350 \mu \mathrm{l}$ of $1 \mathrm{M}$ sodium hydroxide $(\mathrm{NaOH})$ and $40 \mu \mathrm{l}$ of de-ionized water were added to make the final volume $1 \mathrm{~mL}$. Samples were further incubated for $15 \mathrm{~min}$ at room temperature and the absorbance of the samples was measured at $510 \mathrm{~nm}$ in a spectrophotometer (Spectrnics 20, Spectronics, CA). The total flavonoids were determined as qurecetin equivalents per gram of dry mass (mg QE/g dw) and the values were expressed as means of triplicate analysis.

\section{Evaluation of antioxidant capacity}

Total antioxidant activity was estimated by phosphomolybdenum assay method [24] using Molybdate reagent Solution $(1 \mathrm{ml}$ each of $0.6 \mathrm{M}$ sulfuric acid, $28 \mathrm{~mm}$ sodium phosphate and $4 \mathrm{~mm}$ ammonium molybdate were added in $20 \mathrm{ml}$ of distilled water and made up volume to $50 \mathrm{ml}$ by adding distilled water). Extracts in different concentration ranging from $100 \mu \mathrm{l}$ to $500 \mu \mathrm{l}$ were added to each test tube individually containing $3 \mathrm{ml}$ of distilled water and $1 \mathrm{ml}$ of Molybdate reagent solution. These tubes were kept incubated at $95^{\circ} \mathrm{C}$ for $90 \mathrm{~min}$. After incubation, these tubes were normalized to room temperature for 20 $30 \mathrm{~min}$ and the absorbance of the reaction mixture was measured at $655 \mathrm{~nm}$ using a microplate spectrophotometer (Bio-Rad Laboratories, Inc., 2000 Alfred Nobel Drive, CA 94547, USA) against blank sample. Mean values from three independent samples were calculated for each extract. Ascorbic acid (AA) was used as positive reference standard and the total antioxidant capacity was expressed as milligrams of ascorbic acid equivalents per gram of dry mass (mg AAE/g dw).

\section{Determination of ferric reducing antioxidant power (FRAP)}

A modified method [25] was used to measure the ferric ions $\left(\mathrm{Fe}^{3+}\right)$ reducing antioxidant power (FRAP) of extracts. The FRAP method is based on a redox reaction in which an easily reduced oxidant $\left(\mathrm{Fe}^{3+}\right)$, the ferricyanide complex is used in stoichiometric excess and the extracts used as antioxidants, which acts as reductants to reduce the ferricyanide complex to the ferrous form. Briefly, an aliquot of $100 \mu \mathrm{l}$ of different extracts $(5-200 \mathrm{mg} / \mathrm{ml})$ were mixed with $1 \mathrm{ml}$ phosphate buffer $(0.2 \mathrm{M}, \mathrm{pH} 6.6)$ and $1 \mathrm{ml}$ of potassium ferricyanide $(1 \% \mathrm{w} / \mathrm{v})$, shaken well and incubated at $50^{\circ} \mathrm{C}$ for $20 \mathrm{~min}$. After incubation, $1 \mathrm{~mL}$ of trichloroacetic acid $(10 \% \mathrm{w} / \mathrm{v})$ was added to stop the reaction, which was then centrifuged at $3000 \mathrm{rpm}$ for $10 \mathrm{~min}$. After centrifugation, 1.5 $\mathrm{ml}$ supernatant was mixed with $1.5 \mathrm{ml}$ deionized water and $0.1 \mathrm{ml}$ ferric chloride $(0.1 \%)$. The mixture was incubated for $10 \mathrm{~min}$ and absorbance was read at $700 \mathrm{~nm}$ in a spectrophotometer (Spectrnics 20, Spectronics, $\mathrm{CA})$. The assays were carried out in triplicate and the results are expressed as mean values \pm standard deviations. Ascorbic acid was used as standard. The reducing power of the extracts was represented as mg AAE/g of dry mass. Higher absorbance indicates higher reducing power.

\section{DPPH radical scavenging activity}

The antioxidant activities of quinoa seed extracts were assessed [26] on the basis of the radical scavenging effect using stable 1, 1-diphenyl- 
2-picrylhydrazyl (DPPH). DPPH solution $(0.004 \% \mathrm{w} / \mathrm{v})$ was prepared in $95 \%$ methanol and serial dilutions were carried out with the stock solutions $(20 \mathrm{mg} / \mathrm{mL})$ of the extracts. Various concentrations of extracts were mixed with DPPH solution $(900 \mu \mathrm{l})$, incubated in dark for 30 min and then absorbance was measured at $517 \mathrm{~nm}$ (Spectrnics 20, Spectronics, CA). Methanol (95\%), DPPH solution and ascorbic acid (AA) were used as blank, control and reference standard respectively.

DPPH scavenging ability $(\%)=\left[\mathrm{A}_{517 \mathrm{~nm} \text { of control }}-\mathrm{A}_{517 \mathrm{~nm} \text { of sample }} / \mathrm{A}_{517}\right.$ nm of control] X 100

\section{Nitric oxide scavenging activity}

Nitric oxide scavenging activity was determined according to Griess Illosvoy reaction [27] by sodium nitroprusside method [28] in a 96-well microplate. The reaction solution $(50 \mu \mathrm{l})$ containing $10 \mathrm{~mm}$ sodium nitroprusside in PBS ( $\mathrm{pH}$ 7.0) was mixed with $50 \mu \mathrm{l}$ of different concentration $(50-200 \mu \mathrm{g} / \mathrm{ml})$ of sample extracts, followed by incubation at $37^{\circ} \mathrm{C}$ for $20 \mathrm{~min}$ under light. After incubation, $100 \mu \mathrm{L}$ of Griess (Promega) reagent ( $1 \%$ sulfanilamide, $2 \% \mathrm{H}_{3} \mathrm{PO}_{4}$ ) added to each well. Incubate at room temperature for 5-10 minutes, protected from light. A purple/magenta color will begin to form immediately. Absorbance was noted within 30 minutes in a microplate spectrophotometer (Bio-Rad Laboratories, Inc., 2000 Alfred Nobel Drive, CA 94547, USA) at 540 $\mathrm{nm}$ and the results were expressed as per cent of scavenged nitric oxide with respect to the negative control without addition of any antioxidant. Ascorbic acid was used as a positive control.

Nitric oxide scavenging ability $(\%)=\left[\mathrm{A}_{540} \mathrm{~nm}\right.$ of control $\times \mathrm{A}_{540} \mathrm{~nm}$ of sample / $\mathrm{A}_{540} \mathrm{~nm}$ of control] $\times 100$.

\section{Antimicrobial activity}

Briefly, the extracts were tested against the reference strains for antimicrobial activity containing different concentrations of extracts using micro dilution method [29-31] in 96 well micro plates with minor modifications. The antimicrobial activity of the extracts was evaluated against two gram positive (Enterococcus faecalis ATCC 43062, Staphylococcus epidermidis ATCC 33501) and two gram negative (Escherichia coli ATCC 25922, Pseudomonas aeruginosa ATCC 27853) bacterial strains. The culture suspension $(100 \mu \mathrm{l})$ were seeded into $96-$ well plate at $1 \times 10^{4}$ cells/well density and treated with all extracts of quinoa seeds for two different concentrations, $50 \mu \mathrm{g} / \mathrm{ml}$ and $200 \mu \mathrm{g} / \mathrm{ml}$ and incubated for $48 \mathrm{~h}$ at $37 \pm 1^{\circ} \mathrm{C}$ and then $10 \mu \mathrm{l}$ of MTT (Promega) (5 $\mathrm{mg} / \mathrm{ml}$ ) was added to each well. In control experiments, sterile distilled water was added in place of quinoa extracts and only sterile broth was used in place of suspension cultures (without inoculums) as blank. Then absorbance was measured at $570 \mathrm{~nm}$ in a microplate spectrophotometer (Bio-Rad Laboratories, Inc., 2000 Alfred Nobel Drive, CA 94547, USA). All experiments were performed in triplicate.

The percentage inhibition of the extracts was calculated using the formula:

$$
\% \text { Inhibition }=\left(\mathrm{A}_{\text {control }}-\mathrm{A}_{\text {sample }}\right) / \mathrm{A}_{\text {control }} \times 100
$$

\section{Anti-proliferative activity}

Cytotoxic activity of the extract was determined by MTT (Cell Titer 96TM, Promega) assay against a lymphocyte as a preliminary step of experiment by colorimetric assay. Briefly, P 116 T lymphocyte cells were plated at $10^{4}$ cells/well in a 96-well plate. The culture cells were incubated in a humidified incubator at $37^{\circ} \mathrm{C}$, atmosphere of $5 \% \mathrm{CO}_{2}$ and $95 \%$ air for $24 \mathrm{~h}$. After incubation for $24 \mathrm{~h}$ at $37^{\circ} \mathrm{C}$, the medium was discharged and cells were treated by all extracts of quinoa seeds with two different concentrations, $50 \mu \mathrm{g} / \mathrm{ml}$ and $200 \mu \mathrm{g} / \mathrm{ml}$ and incubated for $24 \mathrm{~h}$. MTT reagent $(0.5 \mathrm{mg} / \mathrm{ml})$ was added to each well and further incubated for 4 hours at $37^{\circ} \mathrm{C}$. Viable cells react with MTT to produce purple formazan crystals. After $4 \mathrm{~h}$, the stop solution was added. The cells were then incubated for $2 \mathrm{~h}$ in room temperature and protected from light. After incubation, the cells were shaken. Optical density was read with a microplate spectrophotometer (Bio-Rad Laboratories, Inc., 2000 Alfred Nobel Drive, CA 94547, USA) at a wavelength of $570 \mathrm{~nm}$. The experimental data was absorbance of each well represents viability of cells in each well and then converted to percentage inhibition of growth. All experiments were performed in triplicate.

The percentage inhibition of the extracts was calculated using the formula:

$$
\% \text { Inhibition }=\left(\mathrm{A}_{\text {control }}-\mathrm{A}_{\text {sample }}\right) / \mathrm{A}_{\text {control }} \times 100
$$

\section{Statistical analysis}

Microsoft $^{\oplus}$ Excel 2013 programs were used for statistical analyses and calculations, Data were expressed as mean $(\mathrm{M}) \pm$ standard deviation (SD) for 3 samples in each group. Student's t-test and one way ANOVA were used to compare means, presenting their respective p-value for determination of statistical significance. The difference between compared groups was considered to be significant when $\mathrm{p}<0.05$. Lower case letters a, b, c, d, e, f and $g$ indicate statistical significance.

\section{Results and Discussion}

\section{All extracts and their abbreviations}

Table 1 explained all abbreviations used for different types of extracts. They were designated as QHX-I and QHX-II (for hexane extract), QAC-I and QAC-II (for acetone extract), QMT-I and QMTII (for methanol extract), QET-I and QET-II (for ethanol extract), QEA-I and QEA-II (for ethyl acetate extract), and QWA-I and QWA-II (for water extract). The dried extracts were dissolved in $1 \mathrm{ml}$ dimethyl sulfoxide (DMSO).

\section{Antioxidant and phytochemical activities}

The results of total phenolic content of two different quinoa seed extracts (I and II) have been shown in Table 2. The total phenol content in the quinoa seed extracts (QHX, QAC, QMT, QET, QEA and QWA) expressed as gallic acid equivalent (GAE). The total phenol content in different extracts varied with different solvents and the range was found from $23.74 \pm 1.63 \mathrm{mg} \mathrm{GAE} / \mathrm{g} \mathrm{dw}$ for QHX-II to $89.73 \pm 1.74 \mathrm{mg}$ GAE/g dw for QWA-II, which is the highest total phenolic content. The results were also indicated that the methanol (QMT I and II) and water extracts (QWA I and II) possess a higher level of total phenol content compared to all other extracts. These data indicate major phenolics of quinoa are located in the water derived extracts.

All extracts from different solvents showed a moderately high level of total flavonoid content, the highest level of flavonoid content (106.49

\begin{tabular}{|c|c|c|}
\hline Extracts & Quinoa grain type I & Quinoa grain type II \\
\hline Hexane & QHX-I & QHX-II \\
\hline Acetone & QAC-I & QAC-II \\
\hline Methanol & QMT-I & QMT-II \\
\hline Ethanol & QET-I & QET-II \\
\hline Ethyl acetate & QEA-I & QEA-II \\
\hline Water & QWA-I & QWA-II \\
\hline
\end{tabular}

Table 1: All abbreviations used 


\begin{tabular}{|c|c|c|c|c|}
\hline Type of extract & Total Phenols $^{\mathrm{x}}$ & Total flavonoid ${ }^{Y}$ & Total antioxidant activities ${ }^{z}$ & Ferric reducing antioxidant power ${ }^{z}$ \\
\hline QHX-I & $24.38 \pm 1.28^{b}$ & $41.72 \pm 4.91^{f}$ & $39.13 \pm 0.89^{e}$ & $60.06 \pm 2.32^{\mathrm{d}}$ \\
\hline QHX-II & $23.74 \pm 1.63^{c}$ & $67.37 \pm 16.68^{c}$ & $48.33 \pm 0.58^{f}$ & $61.34 \pm 0.84^{d}$ \\
\hline QAC-I & $27.16 \pm 1.82^{f}$ & $80.85 \pm 5.89^{c}$ & $69.78 \pm 2.37^{f}$ & $133.29 \pm 2.11^{b}$ \\
\hline QAC-II & $37.21 \pm 1.98^{d}$ & $106.49 \pm 10.14^{c}$ & $88.64 \pm 2.37^{g}$ & $134.58 \pm 2.24^{b}$ \\
\hline QMT-I & $49.09 \pm 2.11^{c}$ & $51.83 \pm 6.68^{a}$ & $318 \pm 13.98^{d}$ & $176.65 \pm 12.84^{\mathrm{a}}$ \\
\hline QMT-II & $66.63 \pm 1.23^{d}$ & $72.38 \pm 3.03^{a}$ & $438 \pm 6.98^{h}$ & $183.08 \pm 6.42^{\mathrm{b}}$ \\
\hline QET-I & $38.39 \pm 1.15^{\mathrm{e}}$ & $46.81 \pm 3.45^{\mathrm{a}}$ & $139 \pm 2.25^{d}$ & $155.78 \pm 1.69^{d}$ \\
\hline QET-II & $39.05 \pm 2.25^{b}$ & $65.85 \pm 8.32^{\mathrm{a}}$ & $176 \pm 5.32^{e}$ & $156.63 \pm 0.49^{e}$ \\
\hline QEA-I & $25.02 \pm 0.44^{c}$ & $45.74 \pm 3.48^{b}$ & $53.28 \pm 11.85^{9}$ & $44.01 \pm 0.64^{b}$ \\
\hline QEA-II & $29.09 \pm 3.45^{\mathrm{e}}$ & $50.63 \pm 3.98^{b}$ & $78.03 \pm 4.97^{g}$ & $44.64 \pm 0.32^{b}$ \\
\hline QWA-I & $57.54 \pm 9.01^{\mathrm{c}}$ & $66.94 \pm 13.03^{b}$ & $879 \pm 15.31^{g}$ & $37.25 \pm 0.64^{c}$ \\
\hline QWA-II & $89.73 \pm 1.74^{f}$ & $89.43 \pm 10.75^{c}$ & $1586 \pm 41.42^{\mathrm{g}}$ & $37.47 \pm 0.81^{c}$ \\
\hline
\end{tabular}

$X$ gallic acid, $Y$ quercetin, $Z$ ascorbic acid

Results are expressed as Mean \pm Standard deviation, where $n=3$. Values with different superscripts $(a, b, c, d, e, f, g, h)$ in a column differ significantly $(p<0.05)$.

Table 2: Quantitative representation of antioxidant and phytochemical activities.

$\pm 10.14 \mathrm{mg} \mathrm{QE} / \mathrm{mg} \mathrm{dw}$ ) was found for acetone extract (QAC-II) and the lowest level $(41.72 \pm 4.91 \mathrm{mg} \mathrm{QE} / \mathrm{mg} \mathrm{dw})$ was for hexane extract (QHX-I).

Both methanol extracts (I and II) water extracts (I and II) showed significantly high level of anti-oxidant activities, however the water extracts showed higher level of total antioxidant activities compared to other solvent extracts and the highest level $(1586 \pm 41.42 \mathrm{mg}$ ascorbic $\mathrm{acid} / \mathrm{mg} \mathrm{dw}$ ) of total antioxidant property was observed for QWA-II, as represented in Table 2. These data indicate major phenolics of quinoa are located in the water and also in the methanol derived extracts. Water extracts of quinoa might be considered to have a high level of antioxidant defensive action against reactive oxygen species.

Ferric reducing antioxidant power were observed high for acetone, methanol and ethanol extracts and the highest level $(183.08 \pm 6.42 \mathrm{mg}$ ascorbic acid/mg dw) was for QMT-II, showed in Table 2. Both the extracts of water showed lowest level of ferric reducing antioxidant activities.

\section{DPPH radical scavenging activity}

DPPH scavenging activities are represented in Table 3. The DPPH assay measured hydrogen atom (or one electron) donating activity and hence provided an evaluation of antioxidant activity due to free radical scavenging, 2,2-Diphenyl-lpicrylhydrazyl radical (DPPH) a purplecolored stable free radical is reduced into the yellow colored diphenyl picryl hydrazine [26]. Very significant antioxidant activities were found in all the six extracts for two different seeds at higher concentration 200 $\mu \mathrm{g} / \mathrm{ml}$ (Table 3). Highest DPPH scavenging activities $82.39 \pm 0.03$ and $82.71 \pm 0.03$ were for water extracts. All other extracts (QHX, QAC, QMT, QET and QEA) showed similar DPPH scavenging capacity and the range was $66.56 \pm 0.04$ to $77.47 \pm 0.03$. $\mathrm{IC}_{50}$ values (concentration of the extract in $\mu \mathrm{g} / \mathrm{ml}$ that was able to scavenge half of the DPPH radical) was $14.71 \pm 0.31$ and $14.93 \pm 0.06$, the lowest for water extracts (QWA I and II).

Since, water extracts from both type of seeds showed lowest $\mathrm{IC}_{50}$ value compared to other solvents, this indicates water extracts of quinoa has a strong proton donating ability, which could serve as a free radical scavenger and can neutralize the reactive oxygen species originate due to prolonged oxidative stress in living organisms.

\section{Nitric oxide scavenging activity}

Percentage free radical nitric oxide scavenging activities against concentrations of the extracts have been tabulated in Table 4 . The scavenging activities increased with an increase in concentration of all extracts. Nitric oxide generated from aqueous sodium nitroprusside (SNP) solution interacts with oxygen to produce nitrite ions at physiological $\mathrm{pH}$, which may be quantified and determined according to Griess Illosvoy reaction [28]. All the extracts of quinoa exhibited significant NO scavenging activity in a concentration dependent manner (Table 4). The results clearly identify QEA-II as better NO scavenger where percentage inhibition reached to $88.41 \pm 0.37$ at a concentration $200 \mu \mathrm{g} / \mathrm{ml}$ with an IC50 value of $74.31 \pm 0.27$. Lowest nitric oxide scavenging activity $(26.91 \pm 0.37)$ was observed with water extracts (QWA-II) at a concentration $200 \mu \mathrm{g} / \mathrm{ml}$.

The NO radicals play an important role in inducing inflammatory responses Nitric oxide (NO) is a diffusible free radical that plays many roles as an effectors molecule in diverse biological systems including neuronal messenger, vasodilatation, and antimicrobial and antitumor activities, but Chronic exposure to nitric oxide radical is associated with various carcinomas and inflammatory conditions including juvenile diabetes, multiple sclerosis, arthritis, and ulcerative colitis [32].

\section{Antimicrobial activity}

All extracts of quinoa had shown moderate to significant antimicrobial activities against to both gram positive bacteria $E$. faecalis ATCC 43062, S. epidermidis ATCC 33501 shown in Figures 1(a) and 1(b) and against one of the two gram negative bacteria used, which is P. aeruginosa ATCC 27853 at a concentration $200 \mu \mathrm{g} / \mathrm{ml}$ as shown in Figure 1(c). The extracts from methanol, ethyl acetate and water showed significant antimicrobial activities against $E$. coli ATCC 25922 presented in Figure 1(d) at a concentration $200 \mu \mathrm{g} / \mathrm{ml}$ compared to control. The extracts from hexane, acetone and ethanol did not show any significant activities at this concentration. However, a higher concentration over $200 \mu \mathrm{g} / \mathrm{ml}$ was not tried in this study.

Table 5 representing $\mathrm{IC}_{50}$ values of all cells. All extracts besides extracts from hexane showed moderately low $\mathrm{IC}_{50}$ values against $E$. faecalis ATCC 43062. Methanol extract showed lowest $\mathrm{IC}_{50}$ value (18.75 \pm 0.03 ) against $E$. faecalis ATCC 43062 , whereas, $\mathrm{IC}_{50}$ values were very low and were within the range of $14.55 \pm 0.02$ to $15.59 \pm 0.05$ for all the extracts against $S$. epidermidis ATCC 33501.

Both ethanol and methanol extracts showed lowest $\mathrm{IC}_{50}$ values $19.19 \pm 0.04$ and $16.67 \pm 0.03$ respectively against $P$. aeruginosa ATCC 27853 , and only methanol extract showed lowIC $\mathrm{I}_{50}$ values $20.24 \pm 0.02$ against $E$. coli ATCC 25922. This observation might conclude quinoa seed extracts have antimicrobial activities towards gram positive 
ฮั่

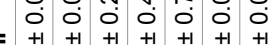

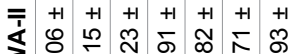

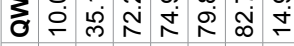

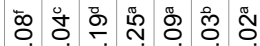

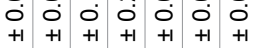

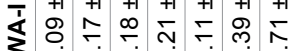

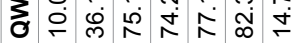

ตั

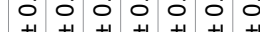

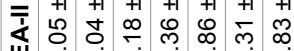

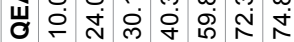

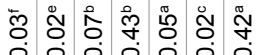

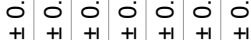

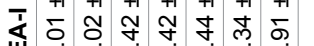

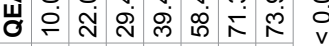
亡

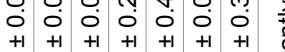

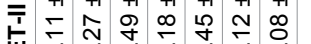

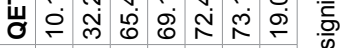

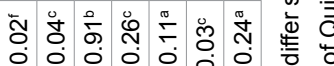

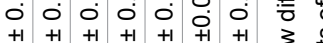

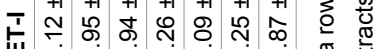

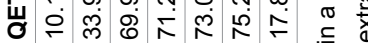
సั่ ปัర

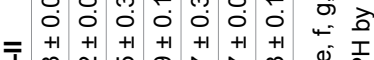

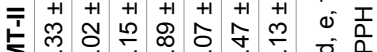

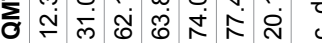

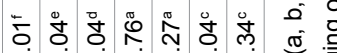

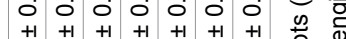

उ ช

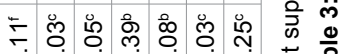

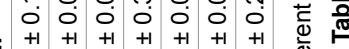
$\overline{\bar{u}} \begin{gathered}+1 \\ 0\end{gathered}$

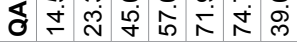

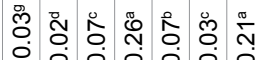

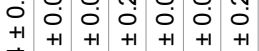

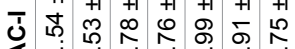
ชั่ กิ่

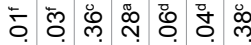

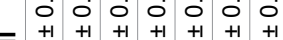

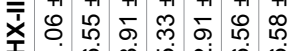

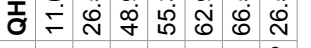

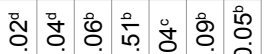

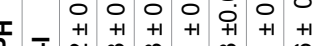

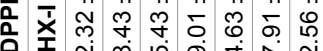

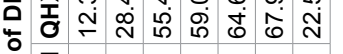

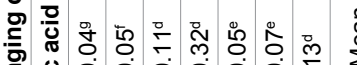
T.

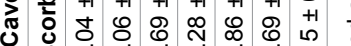

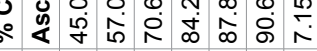

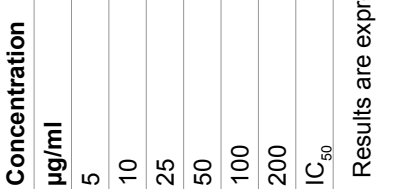

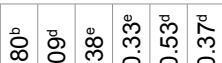

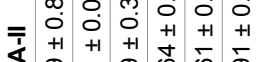

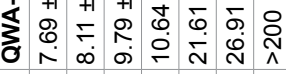

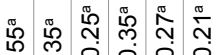

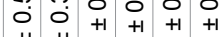

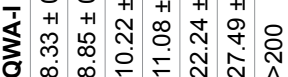

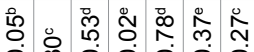

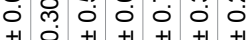

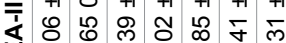

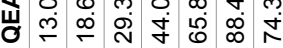

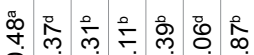

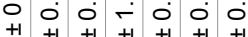

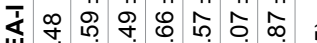

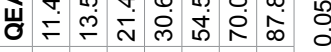

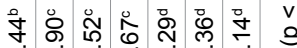
000000

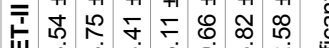

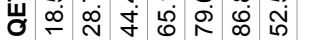

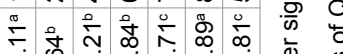

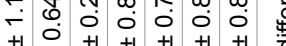

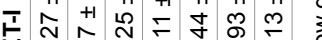

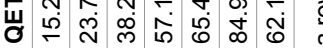

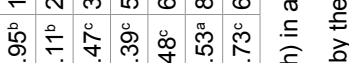
O 00 o 00

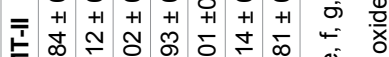

ठำ

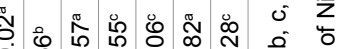

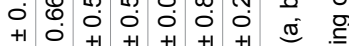

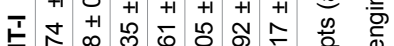

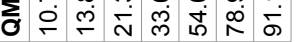

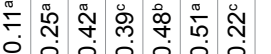

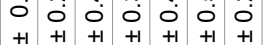

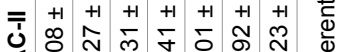

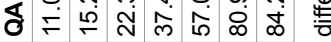

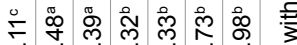

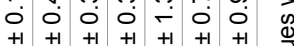

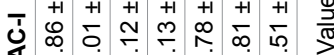

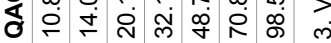

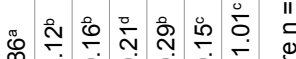

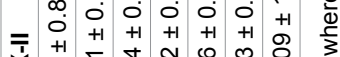

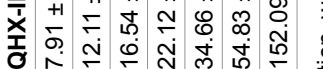
苅 芯

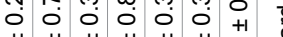

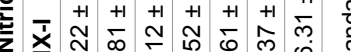

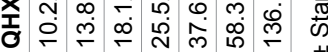

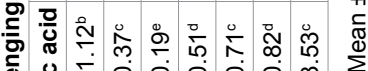

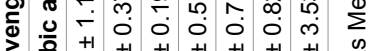
\%

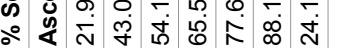

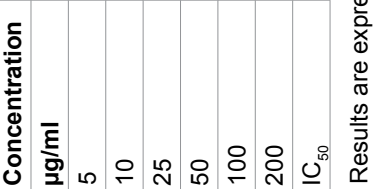

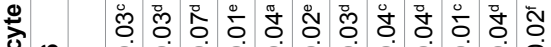

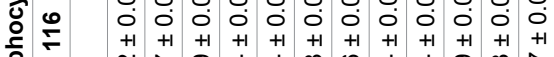
a 3

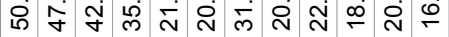

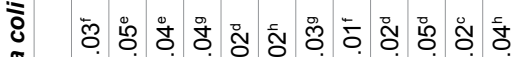

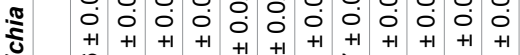
帝 岕

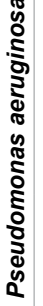

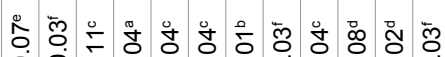

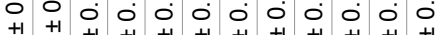

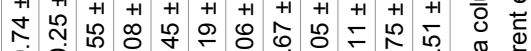

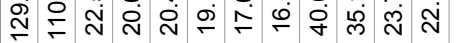

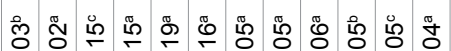

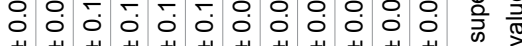
每

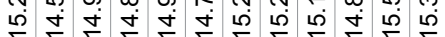

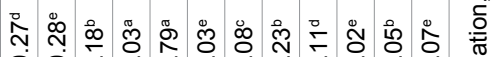

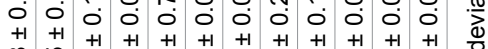

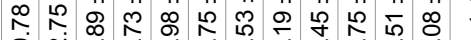

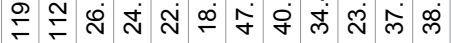
离 $\frac{\pi}{\frac{\pi}{\pi}}$

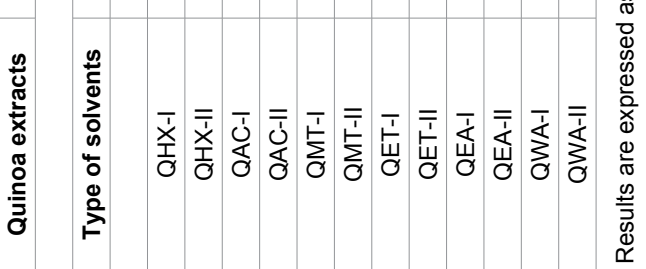


(a)

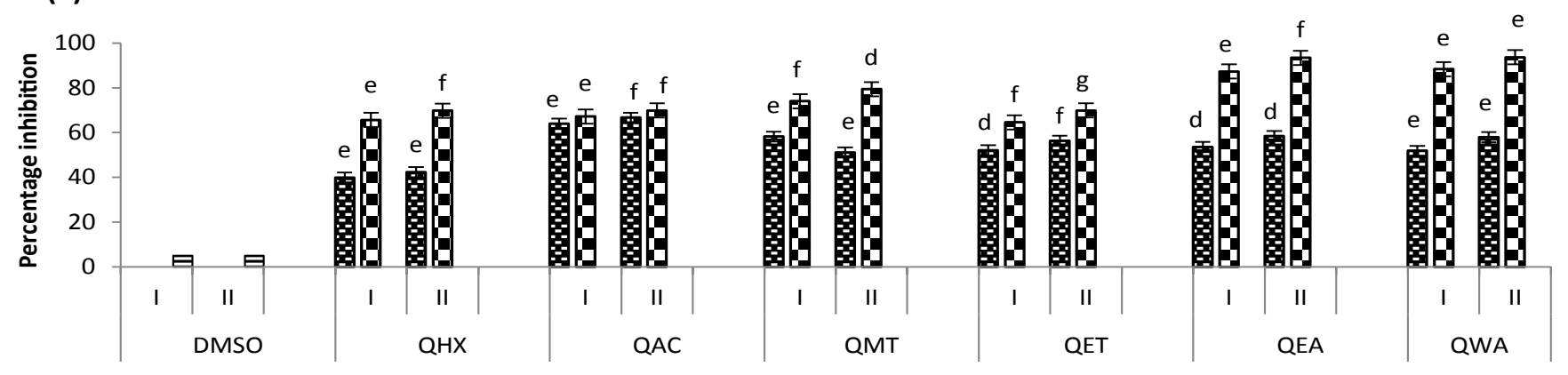

$\mathbf{Q} 50 \mu \mathrm{g} / \mathrm{ml} \boldsymbol{\square} 200 \mu \mathrm{g} / \mathrm{ml}$ 目Control

Figure 1a: Antimicrobial activities of quinova extracts against gram positive bacteria E. faecalis ATCC 43062.

(b)

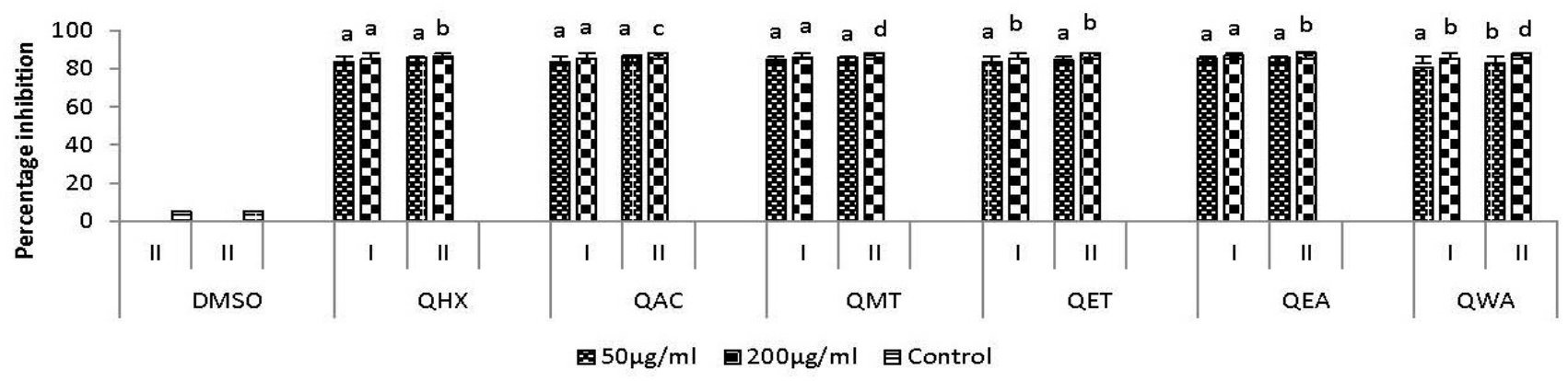

Figure 1b: An antimicrobial activity of quinova extracts against gram positive bacteria S. epidermidis ATCC 33501.

(c)

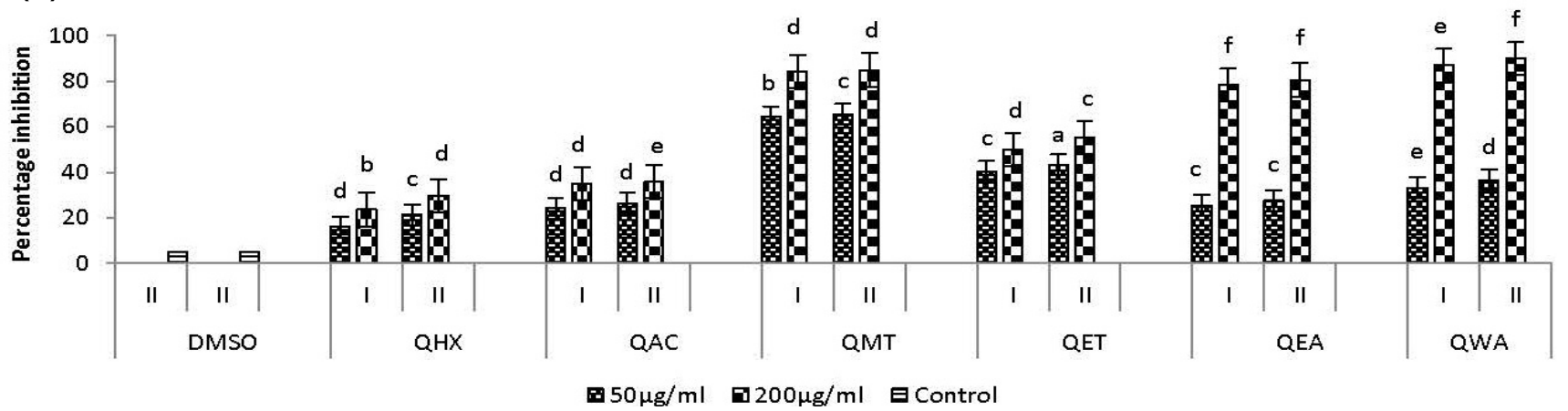

Figure 1c: Antimicrobial activities of quinova extracts against gram negative bacteria $P$. aeruginosa ATCC 27853

bacteria but not to all gram negative bacteria. However, $\mathrm{IC}_{50}$ values are higher for extracts from hexane against $E$. faecalis ATCC 43062 $(119.78 \pm 0.27)$ and $P$. aeruginosa ATCC 27853 (129.74 \pm 0.03$)$. These results also indicate hexane extracts might have limited antimicrobial activities towards both the gram positive and gram negative bacteria. The mechanism could be a further subject of studies.

\section{Anti-proliferative activity}

All extracts of quinoa extracts from all six solvents hexane, methanol, ethanol, ethyl acetate and water showed significant anti proliferative activities against P 116 cells at a concentration of $200 \mu \mathrm{g} /$ $\mathrm{ml}$, represented in Figure 2. However, methanol (QMT-I and QMTII), ethanol (QET-I and QET-II), ethyl acetate (QEA-I and QEA-II) and water (QWA-I and QWA-II) showed significantly low $\mathrm{IC}_{50}$ values ranging from $16.67 \pm 0.02$ (for water extract) to $31.26 \pm 0.03$ (for ethanol extract), as in Table 5. For the crude extracts an $\mathrm{IC}_{50}$ value lower than $30 \mu \mathrm{g} / \mathrm{mL}$ established as the criterion for cytotoxicity [33] by the National Cancer Institute (NCI). Since, water extracts QWA I and QWA II showed lowest IC $_{50}$ values $20.03 \pm 0.04$ and $16.67 \pm 0.02$, water extracts for quinoa should be further studied for its cytotoxic activities.

\section{Conclusion}

The present study clearly demonstrated that the extract of quinoa seeds contains considerable amount of total phenols and flavonoids and exhibits high antioxidant and free radical scavenging activities. In addition, it has been demonstrated that the quinoa seed extracts also is 
Citation: Bhaduri S (2016) An Assessment of Antioxidant and Antiproliferative Activities of Super Grain Quinoa. J Food Process Technol 7: 549. doi:10.4172/2157-7110.1000549

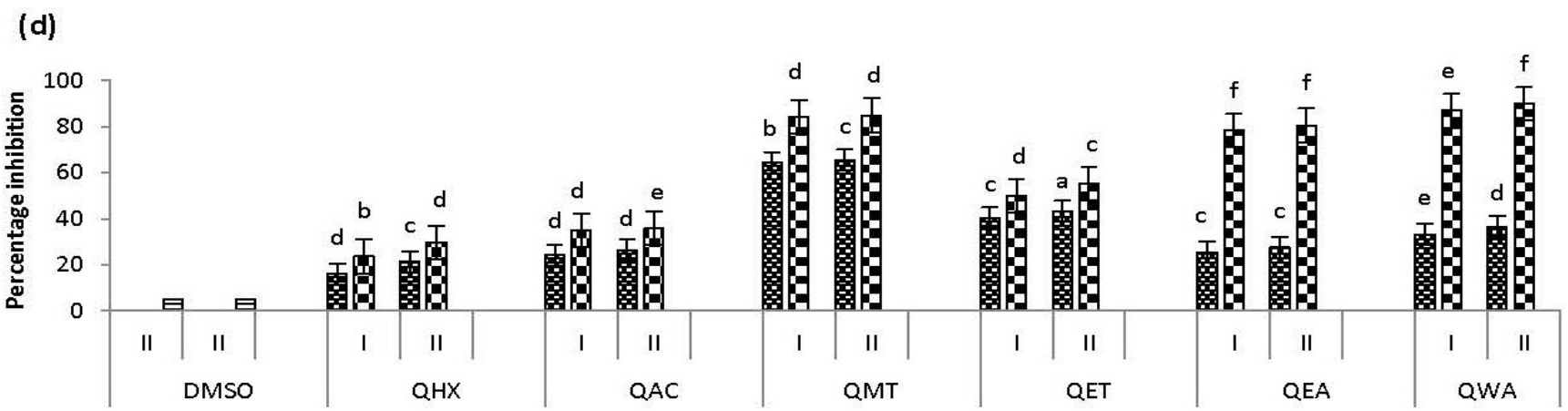

田 $50 \mu \mathrm{g} / \mathrm{ml} 200 \mu \mathrm{g} / \mathrm{ml}$ 日 Control

Figure 1d: Antimicrobial activities of extracts from methanol, ethyl acetate and water against E. coli ATCC 25922.

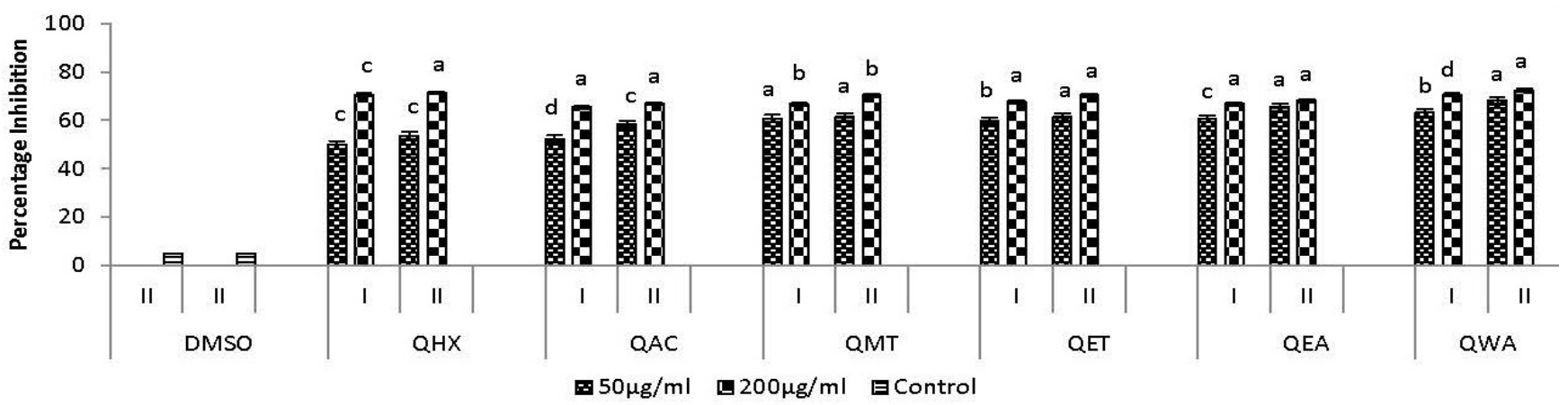

Figure 2: Anti proliferative activities of quinoa extracts from all six solvents hexane, methanol, ethanol, ethyl acetate and water against $P$ 116.

a potential antiproliferative and antimicrobial agent. The antioxidant and biological activities might be due to the synergistic actions of bioactive compounds present in them. However, it is still unclear which components and mechanisms are playing vital roles for these activities. Therefore further investigation is needed to identify the exact moiety responsible for antioxidant and antiproliferative activities of quinoa seeds and also for other gluten free pseudocereals.

\section{Acknowledgments}

The work was supported by PSC-CUNY-TRADA-43-29 grant.

\section{References}

1. Lee SH, Kim SJ, Kim SJ (2014) Anti-oxidant activity with inhibition of osteoclastogenesis by Atractylodes Rhizoma extract. European Review for Medical and Pharmacological Sciences 18: 1806-1812.

2. Nagmoti DM, Khatri DK, Juvekar PR, Juvekar AR (2011) Antioxidant activity and free radical-scavenging potential of Pithecellobium dulce Benth seed extracts. Free Radical and Antioxidants 2: 37-43.

3. Agarwal A, Aponte-Mellado A, Premkumar BJ, Shaman A, Gupta S, et al. (2012) The effects of oxidative stress on female reproduction, a review. Reproductive Biology and Endocrinology.

4. Hollman PCH, Cassidy A, Comte B. Heinonen M, Richelle M, et al. (2011) The Biological Relevance of Direct Antioxidant Effects of Polyphenols for Cardiovascular Health in Humans Is Not Established. J Nutr 141.

5. Guyton KZ, Kensler TW (1993) Oxidative mechanisms in carcinogenesis. Brit Med Bull 49: 523-544.

6. Catherine AR, Nicholas JM, George P (1996) Structure-antioxidant activity relationships of Flavonoids and phenolic acids. Free Radical Biology \&
Medicine 20: 933-956.

7. Green PH, Rostami K, Marsh MN (2005) Diagnosis of coeliac disease. Best Pract. Res. Clin Gastroenterol.

8. Murray JA, Van Dyke C, Plevak MF, Dierkhising RA, Zinsmeister AR, et al. (2003) Trends in the identification and clinical features of celiac disease in a North American community. Clin. Gastroenterol. Hepatol 1: 19-27.

9. Saturni L, Ferretti G, Bacchetti T (2010) The Gluten-Free Diet: Safety and Nutritional Quality. Nutrients 2: 16-34.

10. Bellik Y, Boukraâ L, Alzahrani HA, Bakhotmah BA, Abdellah F, et al. (2013) Molecular Mechanism Underlying Anti-Inflammatory and Anti-Allergic Activities of Phytochemicals: An Update. Molecules 322-353.

11. Gey KF (1986) On the antioxidant hypothesis with regard to arteriosclerosis. Bibl Nutr Dieta 37: 53-91.

12. Arts ICW, Hollman PCH (2005) Polyphenols and disease risk in epidemiological studies. Am J Clin Nutr 81: S317-S325.

13. Laus MN, Gagliardi A, Soccio M, Flagella Z, Pastore D, et al. (2012) Antioxidant Activity of Free and Bound Compounds in Quinoa (Chenopodium quinoa Willd.) Seeds in Comparison with Durum Wheat and Emmer. J Food Science 77: 1150-1155.

14. Bhargava A, Shukla S, Ohri D (2006) Chenopodium quinoa-an Indian perspective. Indus Crops Prodn 23: 73-87.

15. Vega-Galvez A, Miranda M, Vergara J, Uribe E, Puente L, et al. (2010) Nutrition facts and functional potential of quinoa (Chenopodium quinoa willd.), an ancient Andean grain: a review. J Sci Food Agric 90: 2541-2547.

16. Hirose $Y$, Fujita T, Ishii T, Ueno N (2010) Antioxidative properties and flavonoid composition of Chenopodium quinoa seeds cultivated in Japan. Food Chem 119: 1300-1306.

17. Hischenhuber C, Crevel R, Jarry B, Maki M, Moneret-Vautrin DA, et al. (2006) 
Citation: Bhaduri S (2016) An Assessment of Antioxidant and Antiproliferative Activities of Super Grain Quinoa. J Food Process Technol 7: 549. doi:10.4172/2157-7110.1000549

Review article: safe amounts of gluten for patients with wheat allergy or coeliac disease. Alimentary Pharmacology and Therapeutics.

18. Bhaduri S (2013) A Comprenensive study on physical properties of two Glutenfree flour fortified muffins. J Food Processing and technology.

19. Rizzello CG, Coda R, Angelis MD, Cagno RD, Carnevali P, et al. (2009) Longterm fungal inhibitory activity of water-soluble extract from Amaranthus spp. seeds during storage of gluten-free and wheat flour breads. International Journal of Food Microbiology 131: 189-196

20. Negi PS (2012) Plant extracts for the control of bacterial growth: Efficacy, stability and safety issues for food application. International Journal of Food Microbiology 156: 7-17.

21. Choi Y, Jeong HS, Lee J (2007) Antioxidant activity of methanolic extracts from some grains consumed in Korea. Food Chemistry 103: 130-138.

22. Yang J, Paulino R, Janke-Stedronsky S, Abawi F (2007) Free-radicalscavenging activity and total phenols of noni (Morindacitrifolia L.) juice and powder in processing and storage. Food Chemistry 102: 302-308.

23. Barreira JCM, Ferreira ICFR, Oliveira MBPP, Pereira JA (2008) Antioxidant activities of the extracts from chestnut flower, leaf, skins and fruit. Food Chemistry 107: 1106-1113.

24. Prieto P, Pineda M, Aguilar M (1999) Spectrophotometric Quantitation of Antioxidant Capacitythrough the Formation of a Phosphomolybdenum Complex: Specific Application to the Determination of Vitamin E. Analytical Biochemistry 269: 337-341.
25. Oyaizu M (1986) Studies on products of browning reaction prepared from glucoseamine. Jpn J Nutri 44: 307-315.

26. Braca A, Sortino C, Politi M, Morelli I, Mendez J, et al. (2002) Antioxidant activity of flavonoids from Licanialicaniaeflora. Journal of Ethnopharmacology 79: 379-381.

27. Garratt DC (1964) The quantitative analysis of Drugs. Chapman and Hall Ltd, Japan 3: 456-458.

28. Sreejayan NR (1997) Nitric oxide scavenging by curcuminoids. J Pharm Pharmacol 49: 105-107.

29. Camporese A, Balick MJ, Arvigo R, Esposito RG, Morsellino N, et al. (2003) Screening of anti-bacterial activity of medicinal plants from Belize (Central America). J Ethnopharmacol 87: 103-107.

30. NCCLS (2001) National Committee for Clinical Laboratory Standards: Performance Standards for Anti-Microbial Susceptibility Testing. Eleventh Informational Supplement.

31. Gul MZ, Bhakshu LM, Ahmad F, Kondapi AK, Qureshi IA, et al. (2011) Evaluation of Abelmoschusmoschatusextracts for antioxidant, free radical scavenging, antimicrobial and antiproliferative activities using in vitro assays. BMC Complementary and Alternative Medicine 17: 11-64.

32. Boora F, Chirisa E, Mukanganyama S (2014) Evaluation of Nitrite Radical Scavenging Properties of Selected Zimbabwean Plant Extracts and Their Phytoconstituents. Journal of Food Processing.

33. Suffness M, Pezzuto J (1990) Assays related to cancer drug discovery. Methods in Plant Biochemistry: Assay for Bioactivity, Academic Press, London. 